\title{
Detection of the pufferfish toxin tetrodotoxin in European bivalves, England, 2013 to 2014
}

A D Turner (andrew.turner@cefas.co.uk)1, A Powell ${ }^{1}$, A Schofield ${ }^{1,2}$, D N Lees ${ }^{1}$, C Baker-Austin ${ }^{1}$

1. Food Safety Group, Centre for Environment Fisheries and Aquaculture Science, Weymouth, Dorset, United Kingdom

2. Department of Chemistry, University of Hull, Hull, United Kingdom

Citation style for this article:

Turner AD, Powell A, Schofield A, Lees DN, Baker-Austin C. Detection of the pufferfish toxin tetrodotoxin in European bivalves, England, 2013 to 2014 . Euro Surveill. 2015;20(2):pii=21009. Available online: http://www.eurosurveillance.org/ViewArticle.aspx?Articleld=21009

We report the first detection of tetrodotoxins (TTX) in European bivalve shellfish. We demonstrate that TTX is present within the temperate waters of the United Kingdom, along the English Channel, and can accumulate in filter-feeding molluscs. The toxin is heat-stable and thus it cannot be eliminated during cooking. While quantified concentrations were low in comparison to published minimum lethal doses for humans, the results demonstrate that the risk to shellfish consumers should not be discarded.

\section{Background}

Tetrodotoxin (TTX) is the causative agent responsible for pufferfish/fugu poisoning, a fatal marine poisoning found predominantly in tropical regions. It is found mainly in the organs of fish from the Tetraodontidae family, as well as other marine species such as the blue-ringed octopus and gastropods [1]. The toxin and its structural analogues are thought to originate from a variety of marine bacteria, including Vibrio spp. [2].

Clinical effects include a range of neuromuscular symptoms such as paraesthesia of lips and tongue, dizziness and headache, together with gastrointestinal symptoms such as nausea, abdominal pain, diarrhoea and vomiting. Higher degree symptoms include ataxia, incoordination, cardiac arrhythmias, seizures and respiratory failure, leading to death [3]. To date, the only reported occurrences of TTX in bivalve molluscs (clams, cockles, mussels, oysters, scallops and others) have been in New Zealand clams [4] and in Japanese scallops [5]. In European seafood, the only reported occurrence was in 2007. It was detected in the course of a non-fatal human intoxication following consumption of the contaminated sea snail Charonia lampas lampas (a gastropod) harvested in Spain [6]. There has been no evidence for the accumulation of tetrodotoxin in bivalve molluscs grown within European waters to date, and the threat from this toxin is deemed negligible within the European Union. However, with Vibrio spp., reported to be associated with TTX production, detected in United Kingdom shellfish in 2010 [7], and evidence for increasing sea temperatures [8], we aimed to assess the potential for this toxin to accumulate in bivalves grown on the south coast of England, along the Channel.

\section{Testing of bivalve shellfish samples}

Twenty-nine shellfish samples (Mytilus Edulis and Crassostrea gigas), each comprising a minimum of 20 live animals, were harvested between February 2013 and October 2014 from two marine sites on the south coast of England. After shucking, shellfish tissue was prepared for bacterial pathogen detection as previously described [9] and the remainder frozen in storage before chemical analysis. TTXs were analysed in thawed, homogenised shellfish tissues following the methods described by McNabb et al. [4], with a modified shellfish extraction procedure based on [10] and incorporating additional TTX analogues taken from [11]. Hydrophilic interaction chromatography (HILIC) using an ultra performance liquid chromatograph (UPLC) with electrospray ionisation tandem quadrupole mass spectrometry (MS/MS) was used for detection of TTXs. The TTX standard was sourced from Enzo Life Sciences (Exeter, UK).

Two selected reaction monitoring (SRM) transitions were optimised for each of the seven tested toxins, enabling the quantification of toxin concentrations against an external TTX calibration. A Waters Acquity UPLC and Xevo TQ-S MS/MS were optimised for detection of TTX and six TTX congeners (4-epi TTX; 5,6,11-trideoxy TTX; 4,9-anhydro TTX; 11-nor TTX-6-ol; monodeoxy TTX; 11-oxo TTX) based on previous studies $[4,11]$. Semiquantitation of TTX analogues was conducted assuming a relative response factor of 1 to the parent TTX. A second HILIC-MS/MS method based on the detection of TTX dehydration products $\left(C_{9}\right.$ base 2-amino-6-(hydroxymethyl)quinazolin-8-ol) following alkaline derivatisation, was used for additional confirmation [4].

Additionally, Vibrio parahaemolyticus isolated from six of the shellfish samples, and confirmed by PCR targeting species specific markers [9] were cultured in the 


\section{FIGURE A}

Selected reaction monitoring chromatograms obtained following the analysis of tetrodotoxin (TTX) in TTX calibration standard (a), laboratory reference material (b), T23 oyster (c), T22 oyster (d), culture APC6 (e)

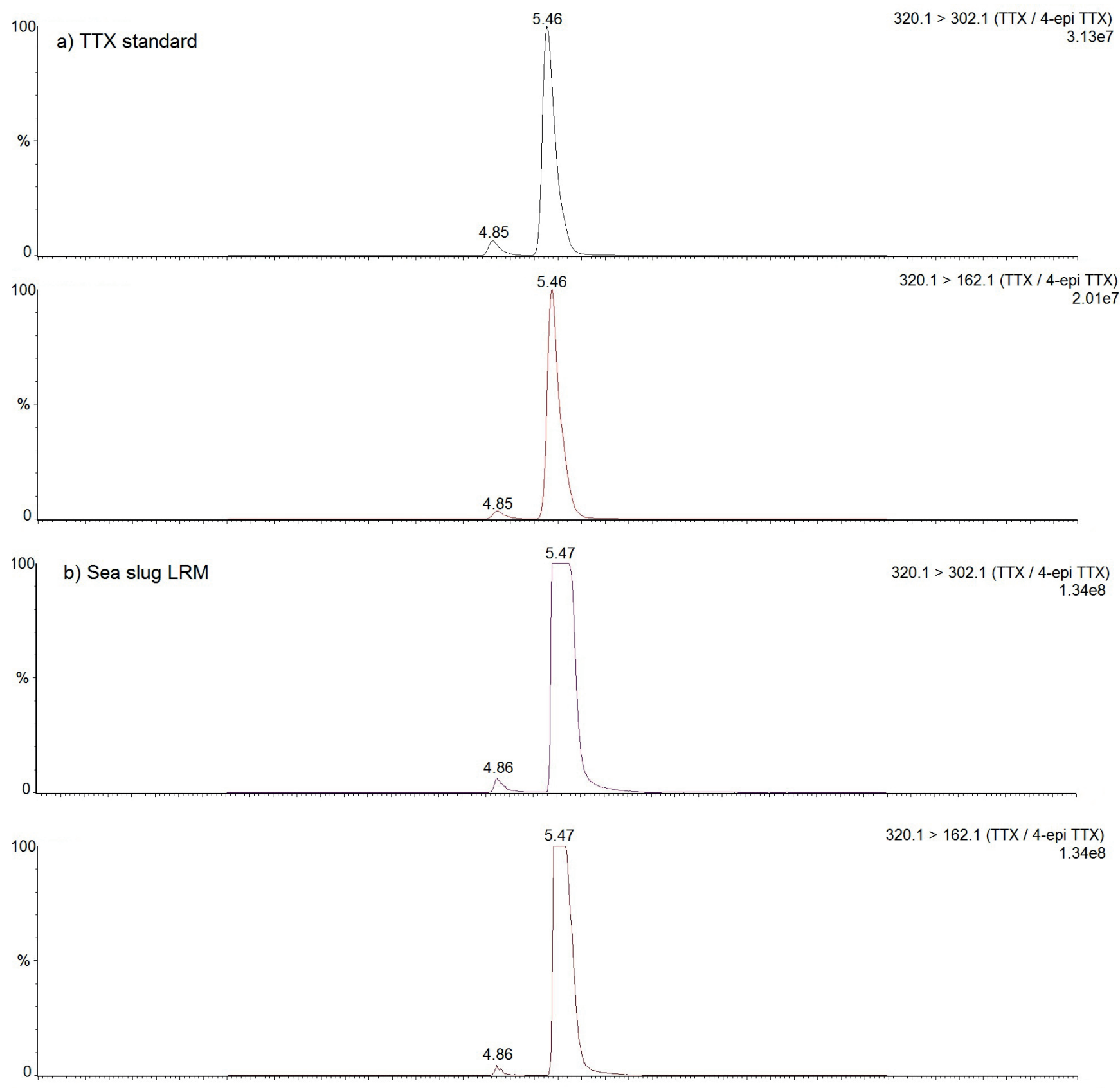

LRM: laboratory reference material; TTX: tetrodotoxin. 


\section{FIGURE B}

Selected reaction monitoring chromatograms obtained following the analysis of tetrodotoxin (TTX) in TTX calibration standard (a), laboratory reference material (b), T23 oyster (c), T22 oyster (d), culture APC6 (e)
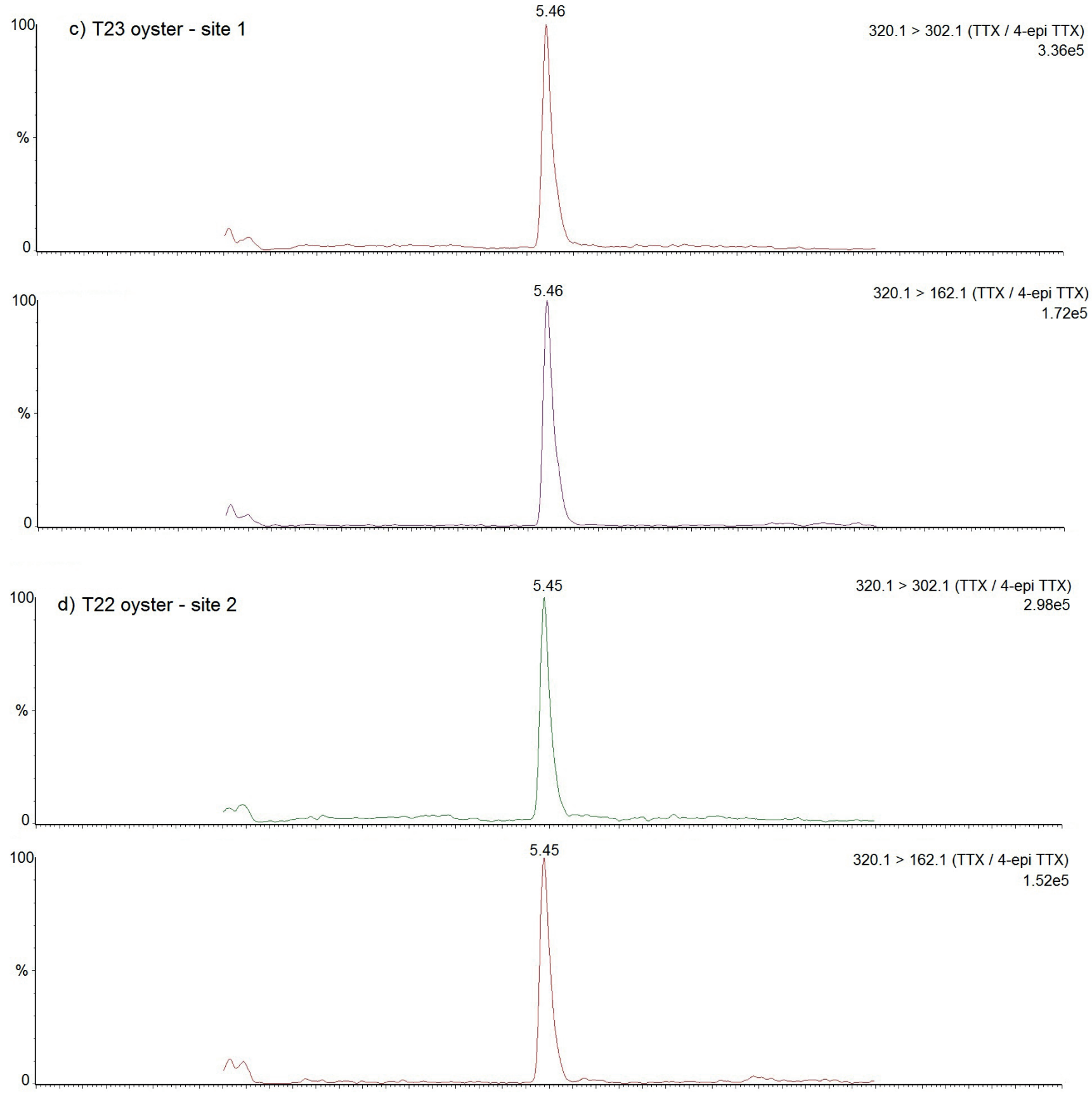

LRM: laboratory reference material; TTX: tetrodotoxin. 
Selected reaction monitoring chromatograms obtained following the analysis of tetrodotoxin (TTX) in TTX calibration standard (a), laboratory reference material (b), T23 oyster (c), T22 oyster (d), culture APC6 (e)

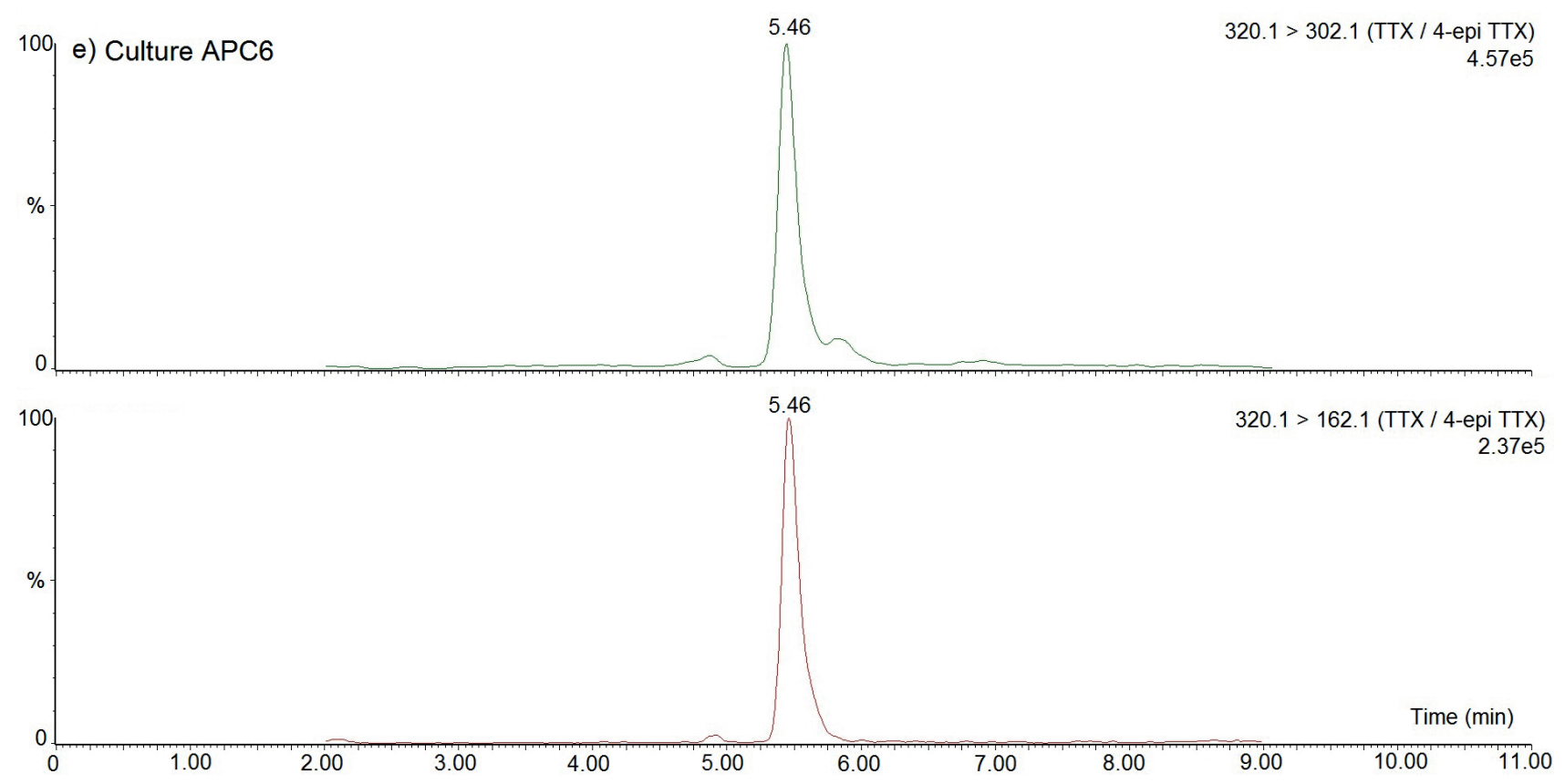

LRM: laboratory reference material; TTX: tetrodotoxin.

laboratory and tested for TTXs. Cultures were centrifuged and the bacterial pellets extracted in $1 \%$ acetic acid before HILIC-MS/MS analysis. Analysis of all unknown samples was conducted alongside two sets of six-level calibration standards and a highly TTX-positive laboratory reference material (LRM) extract prepared from New Zealand Sea Slugs (Pleurobranchaea maculata) [4].

\section{Results}

\section{Bivalve shellfish samples}

Eleven of 29 shellfish samples were found to contain $V$. parahaemolyticus in the shellfish tissue, with one additional sample found to be positive for $V$. cholerae. TTX was detected in 14 of 29 samples, with detection confirmed through the presence of chromatographic peaks for both the primary (quantifier) and secondary (qualifier) SRM transitions, at the same retention time as the TTX standard calibrants and in the LRM (Figures A, B).

The mean primary to secondary SRM peak ratios were $1.87 \pm 0.13(7 \%)$ for the TTX standards and $1.83 \pm 0.26$ (14\%) for the average of all TTX-positive samples.

4-epi TTX was identified in five out of 29 samples, notably those containing the highest TTX concentrations. 5,6,11-trideoxy TTX and 4,9-anhydro TTX were detected in 13 and one sample respectively, with detection confirmed with SRM peaks at the same retention time as those present in the LRM. Detection and semi-quantitation of the $C_{9}$ base product provided a further level of TTX confirmation in the five samples containing the highest concentrations of toxin. The absence of the $C_{9}$ base product in samples containing lower concentrations of TTX is thought to relate to differences in method sensitivity. TTX concentrations ranged from approximately the limit of quantitation (3 $\mu \mathrm{g} \mathrm{TTX/kg} \mathrm{shellfish} \mathrm{tissue)} \mathrm{to} \mathrm{a} \mathrm{maximum} \mathrm{of} 120 \mu \mathrm{g} /$ $\mathrm{kg}$. TTX analogues were quantified at lower levels, typically $10-15 \%$ of the total TTX content (Table 1 ). The maximum summed concentration quantified of all TTX analogues was $137 \mu \mathrm{g}$ TTX/kg in sample T23.

\section{Tetrodotoxins in bacterial cultures}

Eleven bacterial isolates were obtained from six different TTX-contaminated bivalve samples. These were cultured for two days, before being processed for TTX analysis. Ten of the cultures were $V$. parahaemolyticus, with the other isolate $V$. cholerae. TTX was detected in ten of the cultures (Figure C), at concentrations between 42 and $718 \mathrm{ng}$ TTX/L of culture (Table 2), with TTX the only analogue detectable in any of the cultured samples.

\section{Discussion}

Our study reveals, to our best knowledge, the first detection of the causative agent of pufferfish/fugo 
Analysis of bivalve molluscs for Vibrio parahaemolyticus and tetrodotoxins, England, 2013-2014

\begin{tabular}{|c|c|c|c|c|c|c|c|c|c|}
\hline Sample & Date of collection & Site info & Species & Vibrio & TTX $^{\mathrm{a}}$ & 4-ері TTXa & $\begin{array}{c}\text { 5,6,11-trideoxy } \\
\text { TTX }^{\mathrm{a}}\end{array}$ & $\begin{array}{c}\text { 4,9-anhydro } \\
\text { TTX }^{\mathrm{a}}\end{array}$ & $\begin{array}{l}\text { C9 base of } \\
\text { TTX }^{\text {a }}\end{array}$ \\
\hline $\mathrm{T} 1$ & 30 Oct 2013 & Site 1 & $\mathrm{PO}$ & ND & ND & $\mathrm{ND}$ & 5.1 & ND & ND \\
\hline $\mathrm{T}_{2}$ & 17 Dec 2013 & Site 1 & $\mathrm{PO}$ & ND & ND & ND & 2.8 & ND & ND \\
\hline T3 & 17 Dec 2013 & Site 2 & $\mathrm{PO}$ & ND & 11 & ND & ND & ND & ND \\
\hline$T_{4}$ & 26 Feb 2014 & Site 1 & $\mathrm{PO}$ & ND & ND & ND & 4.4 & ND & ND \\
\hline$T_{5}$ & 26 Nov 2014 & Site 2 & $\mathrm{PO}$ & ND & 5.6 & ND & ND & ND & ND \\
\hline T6 & 29 Oct 2013 & Site 2 & PO & ND & 4.4 & ND & ND & ND & ND \\
\hline$T_{7}$ & $29 \operatorname{Jan} 2014$ & Site 2 & $M$ & $Y$ & 3.0 & ND & ND & ND & ND \\
\hline T8 & 29 Jan 2014 & Site 2 & PO & $Y$ & ND & ND & ND & ND & ND \\
\hline T9 & 26 Feb 2014 & Site 2 & $\mathrm{PO}$ & ND & ND & ND & ND & ND & ND \\
\hline T10 & 26 Feb 2014 & Site 2 & $M$ & ND & ND & ND & ND & ND & $\mathrm{ND}$ \\
\hline $\mathrm{T}_{11}$ & 17 Dec 2014 & Site 2 & $\mathrm{PO}$ & $\mathrm{ND}$ & ND & ND & ND & ND & $\mathrm{ND}$ \\
\hline T12 & 29 Jan 2014 & Site 1 & $\mathrm{PO}$ & ND & ND & ND & 2.4 & ND & ND \\
\hline T13 & 27 Aug 2013 & Site 1 & $\mathrm{PO}$ & $\mathrm{ND}$ & 7.6 & ND & ND & ND & $\mathrm{ND}$ \\
\hline T14 & 25 Nov 2013 & Site 1 & $\mathrm{PO}$ & ND & ND & ND & 2.8 & ND & ND \\
\hline T15 & 29 Feb 2013 & Site 1 & $\mathrm{PO}$ & $Y$ & 52 & 2.0 & 3.4 & ND & 37 \\
\hline T16 & 27 Aug 2013 & Site 2 & $\mathrm{PO}$ & $Y$ & 14 & ND & 4.3 & ND & $\mathrm{ND}$ \\
\hline T17 & 26 Feb 2014 & Site 2 & $\mathrm{PO}$ & $Y$ & 15 & ND & 1.3 & ND & ND \\
\hline T18 & 26 Feb 2014 & Site 2 & $M$ & ND & ND & ND & ND & ND & ND \\
\hline T19 & 31 Oct 2013 & Site 2 & $\mathrm{PO}$ & ND & ND & ND & ND & ND & $\mathrm{ND}$ \\
\hline T20 & $29 \mathrm{Jul} 2013$ & Site 2 & $\mathrm{PO}$ & $\mathrm{Y}$ & 14 & 0.4 & 3.1 & ND & ND \\
\hline T21 & 27 Aug 2013 & Site 2 & $\mathrm{PO}$ & ND & 2.7 & ND & ND & ND & ND \\
\hline T22 & 17 Jun 2014 & Site 1 & PO & $\mathrm{Y \dagger}$ & 89 & 2.8 & 6.5 & ND & 76 \\
\hline T23 & 17 Jun 2014 & Site 2 & $\mathrm{PO}$ & $\mathrm{Y}$ & 120 & 3.9 & 11 & 1.8 & 121 \\
\hline T24 & 17 Jun 2014 & Site 2 & M & Y & 39 & 1.2 & 3.8 & ND & 28 \\
\hline T25 & 25 Nov 2013 & Site 2 & $M$ & ND & ND & ND & ND & ND & ND \\
\hline T26 & $29 \mathrm{Jul} 2013$ & Site 2 & $\mathrm{PO}$ & $Y$ & 15 & ND & 1.9 & ND & 22 \\
\hline APF1 & 15 Sep 2014 & Site 2 & $\mathrm{PO}$ & $\mathrm{Y}$ & ND & ND & ND & ND & ND \\
\hline APF2 & 15 Sep 2014 & Site 2 & $M$ & $\mathrm{Y}$ & ND & ND & ND & ND & ND \\
\hline $\mathrm{APF}_{3}$ & 16 Sep 2014 & Site 1 & $\mathrm{PO}$ & ND & ND & ND & ND & ND & ND \\
\hline
\end{tabular}

M: mussels; ND: not detected; PO: Pacific oyster; TTX: Tetrodotoxin; Y: Vibrio spp. detected; Yt: Vibrio cholera detected. ${ }^{a} \mu \mathrm{g}$ per kg shellfish tissue.

poisoning, TTX in bivalve molluscs, mussels and Pacific oysters harvested in Europe. It is also the first detection of TTX in any form within the marine waters of the UK. TTXs are not monitored routinely anywhere in the world for their presence in bivalves, given the absence of published data demonstrating a risk of TTX intoxication from bivalves. The findings reported here are notable given the established assumption that TTXs are associated either with pufferfish or with marine bacteria found exclusively in tropical and sub-tropical oceans and seas $[3,6]$. Here we provide new evidence for the presence of TTX in the temperate waters of the English Channel, thereby extending the range of known occurrences of these important toxins.
TTX was quantified against known standards, with confirmation in positive samples coming from the acquisition of two SRMs, toxin retention time checks and determination of SRM ion ratios. Further confirmation was achieved through detection of TTX $\mathrm{C}_{\text {, }}$ base products. Toxin profiles in the bivalve shellfish were dominated by the parent toxin. With Vibrio cultures containing only TTX, the analogues may result from metabolism by shellfish, as opposed to direct bacterial products. The overall concentrations of TTX were lower than those quantified previously in a sample of the New Zealand bivalve Paphies australis [4]. Interestingly, here also the parent TTX was the only analogue detected in the bacterial culture samples. 
TABLE 2

Analysis of bacterial cultures for tetrodotoxins, England, 2013-2014

\begin{tabular}{|l|c|c|c|}
\hline $\begin{array}{l}\text { Culture } \\
\text { sample }\end{array}$ & Known pathogen & $\begin{array}{c}\text { TTX ng/L } \\
\text { in culture }\end{array}$ & $\begin{array}{c}\text { Associated } \\
\text { shellfish } \\
\text { sample }\end{array}$ \\
\hline APC 1 & Vibrio parahaemolyticus & 59 & T23 \\
\hline APC 2 & V. parahaemolyticus & 67 & T24 \\
\hline APC 3 & V. parahaemolyticus & 42 & T26 \\
\hline APC 4 & V. cholerae & 84 & T22 \\
\hline APC 5 & V. parahaemolyticus & 117 & T17 \\
\hline APC 6 & V. parahaemolyticus & 718 & T24 \\
\hline APC 7 & V. parahaemolyticus & 62 & T23 \\
\hline APC10 & V. parahaemolyticus & ND & T23 \\
\hline APC11 & V. parahaemolyticus & 103 & T24 \\
\hline APC13 & V. parahaemolyticus & 84 & T23 \\
\hline APC14 & V. parahaemolyticus & 116 & T24 \\
\hline
\end{tabular}

ND: not detected; TTX: tetrodotoxin.

The detection of TTX in all but one of the V. parahaemolyticus cultures isolated from bivalve molluscs may be significant, providing additional compelling evidence for the production of TTX by Vibrio spp. The detection of quantifiable levels of TTX in the bivalves in tandem with the detection of Vibrio spp., strengthens the possibility that the bacteria provide the source of the toxin detected in bivalve molluscs, however, further work in this area is clearly necessary. Interestingly, not all TTX-positive bivalves were found to contain Vibrio species, while three of the Vibrio-positive bivalve samples showed no TTX above the limit of detection. However, in the absence of quantitative data for Vibrio, these differences may relate to differences in method sensitivities.

Given the absence of any formal regulatory guidance of TTX in shellfish, the maximum concentration of $137 \mu \mathrm{g} /$ $\mathrm{kg}$ TTX quantified here, equates to $17 \%$ of the maximum permitted level of saxitoxin (STX) equivalents (800 $\mu \mathrm{g}$ STX equivalents/ $\mathrm{kg}$ shellfish tissue), noting the similarity in biological activity between the two toxin groups. $137 \mu \mathrm{g} / \mathrm{kg}$ would also equate to a low level dose of toxin in comparison to the proposed minimum lethal dose (MLD) for TTX of between 0.5 to $2 \mathrm{mg}$ [3]. Consumption of $500 \mathrm{~g}$ of shellfish contaminated with $137 \mu \mathrm{g} / \mathrm{kg}$ of TTXs would equate to the intake of ca 70 $\mu \mathrm{g}$ TTX, ca $14 \%$ of the proposed MLD if taken as 0.5 mg TTX for a $60 \mathrm{~kg}$ human [12]. However, this calculation does not incorporate any additional safety factors as applied by the European Food Standards Agency (EFSA) in their risk assessment methods, taking into account measurement or toxicity-related uncertainties [13], and/or the likely high variability of toxin content in bulk samples of shellfish across harvesting areas.
Consequently, while the human health risk determined from the samples analysed in this study is shown to be low, there is the potential for health impacts, particularly if the levels of TTX were significantly higher at other times or in other areas associated with shellfish harvesting. It is important to note that while bacterial pathogens may be eliminated in shellfish products following effective cooking, TTXs are heat stable and will thus not be destroyed in the food preparation process.

Given the evidence presented here for TTX occurrence in European bivalve molluscs, and the traditional occurrence of these toxins in warm tropical waters, an important question is whether this is linked to increasing sea surface temperatures. The frequency of extreme hot days has increased significantly in the last decade along the margins of the east Atlantic, most notably in the North Sea and English Channel. The frequency of extreme cold periods has also gone down and annual warming is seen to occur earlier in the year on average [8].

\section{Conclusions}

We reveal the presence, for the first time, of the neurotoxin tetrodotoxin in bivalve mollusc shellfish grown at two marine sites along the south coast of England. These toxins have previously been assumed not to occur in bivalve molluscs, particularly in temperate waters. Further, we found an association between the occurrence of TTX and marine Vibrio species both in bivalve molluscs and in bacterial cultures. Given the increasingly favourable conditions for Vibrio proliferation in European waters as sea surface temperatures will possibly rise in the coming decades, we suggest that the potential for occurrence of autochthonous marine bacteria such as Vibrio and TTXs in seafood grown in temperate areas should be more widely investigated.

\section{Acknowledgments}

We thank Andy Selwood at Cawthron Natural Compounds, Nelson, New Zealand, who provided the sample of P. maculata used at Cefas for preparation of the TTX-positive LRM. Paul McNabb, Cawthron Institute, Nelson, New Zealand, for technical discussion relating to the application of the TTX dehydration step for TTX C9 based determination.

Funding for this work was received from the Cefas Seedcorn budget.

Conflicts of interest

None declared.

Authors' contributions

AT and AP designed the study. AP performed the sample preparation and bacterial analysis. CBA performed molecular confirmation of Vibrio strain. AS and AT extracted and SPE-cleaned the shellfish. AT performed HILIC-MS/MS quantitation of TTXs in shellfish extracts and bacterial cultures. AT, AP, DL and CBA discussed the results and participated in the writing. 


\section{References}

1. Isbister GK, Kiernan MC. Neurotoxic marine poisoning. Lancet Neurol. 2005;4(4):219-28. http://dx.doi.org/10.1016/S14744422(05)70041-7 PMID:15778101

2. Pratheepa V, Vasconcelos V. Microbial diversity associated with tetrodotoxin production in marine organisms. Environ Toxicol Pharmacol. 2013;36(3):1046-54. http://dx.doi. org/10.1016/j.etap.2013.08.013 PMID:24121556

3. Noguchi T, Onuki K, Arakawa O. Tetrodotoxin poisoning due to pufferfish and gastropods, and their intoxication mechanism. ISRN Toxicology. 2011. 1-10. http://dx.doi. $\operatorname{org} / 10.5402 / 2011 / 276939$

4. McNabb PS, Taylor DI, Ogilvie SC, Wilkinson L, Anderson A, Hamon D, et al. First detection of tetrodotoxin in the bivalve Paphies australis by liquid chromatography coupled to triple quadrupole mass spectrometry with and without precolumn reaction. J AOAC Int. 2014;97(2):325-33. PMID:24830143

5. Kodama M, Sato S, Ogata T. Alexandrium tamarense as a source of Tetrodotoxin in the scallop Patinopecten yessoensis. Toxic phytoplankton Blooms in the Sea (Eds. T.J. Smayda and Y. Shimizu). Amsterdam: Elsevier Science Publishers B.V. 1993.

6. Rodriguez P, Alfonso A, Vale C, Alfonso C, Vale P, Tellez A, et al. First toxicity report of tetrodotoxin and 5,6,11-trideoxyTTX in the trumpet shell Charonia lampas lampas in Europe. Anal Chem. 2008;80(14):5622-9. http://dx.doi.org/10.1021/ ac800769e PMID:18558725

7. Baker-Austin C, Stockley L, Rangdale R, Martinez-Urtaza J. Environmental occurrence and clinical impact of Vibrio vulnificus and Vibrio parahaemolyticus: a European perspective. Environ Microbiol Rep. 2010;2(1):7-18. http:// dx.doi.org/10.1111/j.1758-2229.2009.00096.x PMID:23765993

8. Lima FP, Wethey DS. Three decades of high-resolution coastal sea surface temperatures reveal more than warming. Nat Commun. 2012;3:704. http://dx.doi.org/10.1038/ncomms1713 PMID:22426225

9. Powell A, Baker-Austin C, Wagley S, Bayley A, Hartnell R. Isolation of Pandemic Vibrio parahaemolyticus from UK Water and Shellfish Produce. Microb Ecol. 2013;65(4):924-7. http:// dx.doi.org/10.1007/s00248-013-0201-8 PMID:23455432

10. Lawrence JF, Niedzwiadek B, Menard C. Quantitative determination of Paralytic Shellfish Poisoning Toxins in Shellfish using Pre-Chromatographic Oxidation and Liquid Chromatography with Fluorescence Detection. J AOAC Int. 2005;88(6):1714-32. PMid:16526455.

11. Yotsu-Yamashita M, Jang J-H, Cho Y, Konoki K. Optimisation of simultaneous analysis of Tetrodotoxin, 4-epitetrodotoxin, 4,9-anhydrotetrodotoxin and 5,6,11-trideoxytetrodotoxin by hydrophilic interaction liquid chromatography-tandem mass spectrometry. Forensic Toxicol. 2011;29(1):61-4. http://dx.doi. org/10.1007/S11419-010-0106-x

12. Arakawa O, Hwang D-F, Taniyama S, Takatani T. Toxins of pufferfish that cause human intoxication. In: Coastal Environmental and Ecosystem Issues of the East China Sea. (Eds: A. Ishimatsu and H.-J. Lie). Tokyo: Terrpub and Nagaski University. 2010.

13. European Food Safety Authority (EFSA). Marine biotoxins in shellfish - Saxitoxin group. Scientific Opinion of the Panel on Contaminants in the Food Chain. The EFSA Journal. 2009;1019, $1-76$. 